\title{
RESEARCH
}

Open Access

\section{Triglyceride glucose index is a useful marker for predicting subclinical coronary artery disease in the absence of traditional risk factors}

Gyung-Min Park ${ }^{1+}$, Young-Rak Cho ${ }^{2+}$, Ki-Bum Won $^{1 *}$ (D), Yu Jin Yang ${ }^{1,3}$, Sangwoo Park ${ }^{1}$, Soe Hee Ann ${ }^{1}$, Yong-Giun Kim', Eun Ji Park', Shin-Jae Kim', Sang-Gon Lee', Dong Hyun Yang ${ }^{5}$, Joon-Won Kang ${ }^{5}$, Tae-Hwan Lim', Hong-Kyu Kim', Jaewon Choe ${ }^{6}$, Seung-Whan Lee ${ }^{3}$ and Young-Hak Kim ${ }^{3}$

\begin{abstract}
Background: Atherosclerotic cardiovascular (CV) events commonly occur in individuals with a low CV risk burden. This study evaluated the ability of the triglyceride glucose (TyG) index to predict subclinical coronary artery disease (CAD) in asymptomatic subjects without traditional CV risk factors (CVRFs).

Methods: This retrospective, cross-sectional, and observational study evaluated the association of TyG index with CAD in 1250 (52.8 \pm 6.5 years, $46.9 \%$ male) asymptomatic individuals without traditional CVRFs (defined as systolic/ diastolic blood pressure $\geq 140 / 90 \mathrm{mmHg}$; fasting glucose $\geq 126 \mathrm{mg} / \mathrm{dL}$; total cholesterol $\geq 240 \mathrm{mg} / \mathrm{dL}$; low-density lipoprotein cholesterol $\geq 160 \mathrm{mg} / \mathrm{dL}$; high-density lipoprotein cholesterol $<40 \mathrm{mg} / \mathrm{dL}$; body mass index $\geq 25.0 \mathrm{~kg} / \mathrm{m}^{2}$; current smoking; and previous medical history of hypertension, diabetes, or dyslipidemia). CAD was defined as the presence of any coronary plaque on coronary computed tomographic angiography. The participants were divided into three groups based on TyG index tertiles.

Results: The prevalence of CAD increased with elevating TyG index tertiles (group I: $14.8 \%$ vs. group II: 19.3\% vs. group III: 27.6\%; $P<0.001)$. Multivariate logistic regression models showed that TyG index was associated with an increased risk of CAD (odds ratio [OR] 1.473, 95\% confidence interval [CI] 1.026-2.166); especially non-calcified (OR $1.581,95 \% \mathrm{Cl} 1.002-2.493$ ) and mixed plaques (OR 2.419, 95\% Cl 1.051-5.569) (all $P<0.05$ ). The optimal TyG index cut-off for predicting CAD was 8.44 (sensitivity 47.9\%; specificity 68.5\%; area under the curve $0.600 ; P<0.001$ ). The predictive value of this cut-off improved after considering the non-modifiable factors of old age and male sex.
\end{abstract}

Conclusions: TyG index is an independent marker for predicting subclinical CAD in individuals conventionally considered healthy.

Keywords: Triglyceride glucose index, Atherosclerosis, Risk factor, Coronary computed tomographic angiography

\footnotetext{
*Correspondence: kbwon99@naver.com

${ }^{\dagger}$ Gyung-Min Park and Young-Rak Cho contributed equally to this work.

${ }^{1}$ Division of Cardiology, Ulsan University Hospital, University of Ulsan College

of Medicine, 877 Bangeojinsunhwando-ro, Dong-gu, Ulsan 44033, Republic

of Korea

Full list of author information is available at the end of the article
}

(c) The Author(s). 2020 Open Access This article is distributed under the terms of the Creative Commons Attribution 4.0 International License (http://creativecommons.org/licenses/by/4.0/), which permits unrestricted use, distribution, and reproduction in any medium, provided you give appropriate credit to the original author(s) and the source, provide a link to the Creative Commons license, and indicate if changes were made. The Creative Commons Public Domain Dedication waiver (http://creativecommons.org/publicdomain/zero/1.0/) applies to the data made available in this article, unless otherwise stated. 


\section{Background}

Cardiovascular (CV) risk is clinically stratified based on traditional CV risk factors (CVRFs) in asymptomatic individuals [1]. However, although most adverse CV events are closely related to traditional CVRFs, atherosclerotic $\mathrm{CV}$ events commonly occur in individuals with a low $\mathrm{CV}$ risk burden [2-4]. According to current recommendations for primary prevention [5], asymptomatic individuals without CVRFs are usually not considered a target for preventive strategies, regardless of the potential presence of atherosclerosis. Recently, the Progression of Early Subclinical Atherosclerosis (PESA) study reported the noticeable results that subclinical atherosclerosis was observed in about $50 \%$ of the CVRF-free middle-aged population [6]. Despite some limitation of PESA study in that obesity was not included in CVRFs, this finding highlights the significance of identifying independent predictors for subclinical atherosclerosis in the absence of traditional CVRFs considering that subclinical atherosclerosis underlies most $\mathrm{CV}$ events. Although recent study has focused on the significance of low-density lipoprotein cholesterol (LDL-C) for subclinical coronary artery disease (CAD) in asymptomatic adults without CVRFs [7], data on the independent predictor for subclinical atherosclerosis in this population has been scarce in clinical practice.

Insulin resistance (IR) has been demonstrated to play an important role in CAD $[8,9]$. The triglyceride glucose (TyG) index, which is calculated from fasting measurements of triglycerides and glucose, has been recently suggested as a reliable surrogate marker of IR [10-12]. Several previous studies have shown that TyG index is associated with coronary atherosclerosis $[13,14]$. However, whether TyG index is a useful predictor of coronary atherosclerosis in healthy individuals with a low $\mathrm{CV}$ risk burden has not been determined. In the present study, we examined the association between TyG index and subclinical $\mathrm{CAD}$ in individuals without traditional CVRFs.

\section{Methods}

\section{Study design and population}

In this retrospective, cross-sectional, and observational study, a total of 8945 Korean individuals aged $\geq 40$ years who had undergone self-referred coronary computed tomography angiography (CCTA) evaluation as part of a general health examination were consecutively enrolled at the Health Screening and Promotion Center of the Asan Medical Center between January 2007 and December 2011 [15]. Among these, 2023 individuals refused to participate in this study. Subsequently, 4972 were gradually excluded because of (a) a history of angina or myocardial infarction $(n=336)$; (b) abnormal resting electrocardiography results, including pathological Q waves, ischemic ST segments, $\mathrm{T}$ wave changes, or left bundle-branch blocks $(n=205)$; (c) structural heart disease $(n=49)$; (d) a history of open heart surgery $(n=5)$; (e) a history of percutaneous coronary intervention $(n=5)$; (f) a previous cardiac procedure $(n=10)$; $(\mathrm{g})$ renal insufficiency, defined as serum creatinine $\geq 0.13 \mathrm{mmol} / \mathrm{L}(\geq 1.5 \mathrm{mg} / \mathrm{dL})(n=1)$; (h) traditional CVRFs, defined as fasting glucose $\geq 126 \mathrm{mg} / \mathrm{dL}$, hemoglobin A1C (HbA1C) levels $\geq 6.5 \%$, or previous medical history of diabetes $(n=1105)$; systolic blood pressure $\geq 140 \mathrm{mmHg}$, diastolic blood pressure $\geq 90 \mathrm{mmHg}$, or previous medical history of hypertension $(n=1727)$; total cholesterol $\geq 240 \mathrm{mg} / \mathrm{dL}$, LDL-C $\geq 160 \mathrm{mg} / \mathrm{dL}$, high-density lipoprotein cholesterol (HDL-C) $<40 \mathrm{mg} / \mathrm{dL}$, or previous medical history of dyslipidemia $(n=1199)$; body mass index (BMI) $\geq 25.0 \mathrm{~kg} / \mathrm{m}^{2}(n=659)$; and current smoking $(n=290)$; or (i) incomplete laboratory data $(n=81)$. Finally, 1250 asymptomatic individuals were enrolled in the present study (Additional file 1: Figure S1). The study protocol was approved by the local ethics committee of Asan Medical Center. All patients provided written informed consent.

Basic demographic data were acquired from a database maintained by the Health Screening and Promotion Center of Asan Medical Center. All medical history was collected using a systematic questionnaire conducted before a general health examination. Height and weight measurements were obtained while the participants wore light clothing without shoes. BMI was calculated as weight in kilograms divided by the square of the height in meters. Obesity was defined as a BMI of $\geq 25.0 \mathrm{~kg} / \mathrm{m}^{2}$, based on the cut-offs for Asian populations. Blood pressure was measured using an automatic manometer with an appropriate cuff size after the participants rested for $\geq 5 \mathrm{~min}$. Blood samples were drawn from the antecubital vein into vacuum tubes after the participants fasted overnight and were analyzed at the certified central laboratory of Asan Medical Center. Total cholesterol, triglyceride, LDL, HDL, uric acid, and creatinine were measured by the enzymatic colorimetric method using a Toshiba 200FR Neo (Toshiba Medical System Co., Ltd., Tokyo, Japan). Fasting glucose was measured by the enzymatic colorimetric method using a Toshiba 200 FR auto-analyzer (Toshiba). Ion-exchange high-performance liquid chromatography (Bio-Rad Laboratories, Inc., Hercules, CA) was performed for the measurement of HbA1C. The TyG index was calculated as ln [fasting triglycerides $(\mathrm{mg} / \mathrm{dL}) \times$ fasting glucose $(\mathrm{mg} / \mathrm{dL}) / 2$ ]. Family history of CAD was defined as CAD in a first-degree relative of any age. The Framingham risk score was calculated for all participants [16-18].

\section{Acquisition and analysis of CCTA images}

CCTA was performed using a dual-source CT scanner (Somatom Definition; Siemens, Erlangen, Germany) or a 
single-source 64-slice CT scanner (LightSpeed VCT; GE, Milwaukee, WI). Patients without contraindications to beta-adrenergic blocking agents and with initial heart rates $>65 \mathrm{bpm}$ received an oral dose of $2.5-\mathrm{mg}$ bisoprolol (Concor, Merck, Darmstadt, Germany) $1 \mathrm{~h}$ before the CT examination. CT scanning was performed in the retrospective ECG-gating mode with ECG-based tube current modulation or the prospective ECG-triggering mode. Before contrast injection, isosorbide dinitrate (Isoket spray; Schwarz Pharma, Monheim, Germany) was used. Following this, $60-80 \mathrm{~mL}$ of iodinated contrast (Iomeron 400; Bracco, Milan, Italy) was injected at 4 $\mathrm{mL} / \mathrm{s}$, followed by a $40-\mathrm{mL}$ saline flush during CCTA acquisition. The region of interest was placed in the ascending aorta, and image acquisition was automatically initiated once a selected threshold (100 HU) had been reached using bolus tracking. A standard scanning protocol was used and the tube voltage and tube current-time product were adjusted according to the patient's body size as follows: 100 or $120 \mathrm{kVp}$ tube voltage; 240-400 mA per rotation (dual-source CT), and 400$800 \mathrm{~mA}$ (64-slice CT) tube current. The size-specific dose estimate was calculated using the patient's body diameter [19]. The mean effective dose for our CT protocol was $7.6 \pm 5.1 \mathrm{mSv}$. All CCTA images were analyzed using a dedicated workstation (Advantage Workstation, GE; or Volume Wizard, Siemens) by experienced cardiovascular radiologists (D.H.Y., J.-W.K., and T.-H.L.) according to the Society of Cardiovascular Computed Tomography's guidelines [20]. The coronary artery calcium score (CACS) was determined as previously described [21]. CACS was categorized into five groups: 0, $1-10,11-100,101-400$, and $>400$. Plaques were defined as structures $\geq 1 \mathrm{~mm}^{2}$ within and/or adjacent to the vessel lumen, which were clearly distinguishable from the lumen and the surrounding pericardial tissue. Plaques without calcium were classified as non-calcified, those with calcified tissue comprising $\geq 50 \%$ of the plaque area (density $>130 \mathrm{HU}$ ) were classified as calcified, and those with $<50 \%$ calcium were classified as mixed plaques [22]. The contrast-enhanced portion of the lumen was semiautomatically traced at the site of maximal stenosis and compared with the mean value of the proximal and distal reference sites [23]. CAD was defined as the presence of any coronary plaque.

\section{Statistical analysis}

Continuous variables are expressed as mean \pm SD. Categorical variables are presented as absolute values and proportions. Continuous variables were compared using one-way analysis of variance. Categorical variables were compared using the $\chi^{2}$-test or Fisher's exact test, as appropriate. Univariate regression analysis was performed to evaluate the association between clinical variables and
CAD. Variables with $P<0.05$ on univariate analysis were considered as confounding factors and entered the multivariate regression analysis. ROC curve analysis using the Youden index was conducted to determine the optimal TyG index cut-off for predicting CAD. All statistical analyses were performed using the Statistical Package for the Social Sciences version 19 (SPSS, Chicago, Il) and SAS version 9.1.3 (SAS Institute Inc., Cary, NC). A $P$-value of $<0.05$ was considered significant for all analyses.

\section{Results}

\section{Baseline characteristics}

Table 1 shows the clinical characteristics of the study cohort. The mean age of the 1250 participants (586 men, $46.9 \%)$ was $52.8 \pm 6.5$ years; 75 (6\%) participants were older than 65 years. All participants were divided into three groups based on TyG index tertiles. The mean TyG indices were $7.84 \pm 0.19,8.27 \pm 0.11$, and $8.83 \pm 0.30$ in groups I (lowest), II, and III (highest), respectively. There was no significant difference in age among the three groups. Systolic and diastolic blood pressure, BMI, Framingham risk score, the levels of total cholesterol, triglyceride, LDL-C, creatinine, fasting glucose, HbA1C, and uric acid, and the prevalence of male sex significantly increased with increasing tertiles. The levels of HDL-C significantly decreased with increasing tertiles. The overall prevalence of CAD was $20.6 \%$. Compared with participants $<65$ years, those $\geq 65$ years had a significantly higher prevalence of CAD $(18.5 \%$ vs. $53.3 \%$, $P<0.001$ ) (Additional file 2: Figure S2A). Men had a higher prevalence of CAD than women $(33.8 \%$ vs. $8.9 \%$, $P<0.001$ ) (Additional file 2: Figure S2B). The prevalence of categorical CACS was significantly different among the three groups. The prevalence of any, calcified, noncalcified, and mixed plaque significantly increased with increasing tertiles.

Association between clinical variables and subclinical CAD Univariate regression analysis showed that age; male sex; systolic and diastolic blood pressure; BMI; and the levels of LCL-C, HDL-C, and uric acid were significantly associated with the risk of CAD. Compared with that in group I, the risk of CAD was significantly higher in group III (OR $2.200,95 \%$ CI 1.555-3.113, $P<0.001$ ) (Table 2).

\section{Impact of TyG index on coronary plaques}

Univariate regression analysis showed that TyG index was associated with an increased risk of CAD (OR 2.158, 95\% CI 1.605-2.903, $P<0.001)$. In multivariate regression analysis, TyG index had an incremental impact on CAD (OR 1.473, 95\% CI 1.026-2.166, $P=0.036$ ). Regarding coronary plaque subtypes, multivariate regression analysis showed that TyG index was independently associated with 
Table 1 Clinical characteristics

\begin{tabular}{|c|c|c|c|c|c|}
\hline & Total $(n=1250)$ & Tertile of TyG index & & & \\
\hline & & $\begin{array}{l}\text { ( (lowest) }(n=413) \\
6.98-8.08\end{array}$ & $\begin{array}{l}\text { II }(n=424) \\
8.09-8.47\end{array}$ & $\begin{array}{l}\text { III (highest) }(n=413) \\
8.48-10.17\end{array}$ & $P$ \\
\hline Age, years & $52.8 \pm 6.5$ & $52.3 \pm 6.4$ & $52.7 \pm 6.6$ & $53.2 \pm 6.5$ & 0.133 \\
\hline Age $\geq 65$ years, $n(\%)$ & $75(6)$ & $20(4.8)$ & $26(6.1)$ & $29(7.9)$ & 0.415 \\
\hline Male, n (\%) & $586(46.9)$ & $156(37.8)$ & $181(42.7)$ & $249(60.3)$ & $<0.001$ \\
\hline Systolic BP, mmHg & $113.2 \pm 10.7$ & $111.6 \pm 10.8$ & $112.5 \pm 10.4$ & $115.5 \pm 10.4$ & $<0.001$ \\
\hline Diastolic BP, mmHg & $71.3 \pm 8.8$ & $69.9 \pm 8.9$ & $70.5 \pm 8.9$ & $73.6 \pm 8.2$ & $<0.001$ \\
\hline $\mathrm{BMl}, \mathrm{kg} / \mathrm{m}^{2}$ & $22.2 \pm 1.7$ & $21.7 \pm 1.9$ & $22.2 \pm 1.6$ & $22.8 \pm 1.5$ & $<0.001$ \\
\hline Family history of CAD, n (\%) & $196(15.7)$ & $53(12.8)$ & $63(14.9)$ & $80(19.4)$ & 0.030 \\
\hline Framingham risk score & $3.9 \pm 2.9$ & $2.8 \pm 2.4$ & $3.5 \pm 2.5$ & $5.3 \pm 3.2$ & $<0.001$ \\
\hline Total cholesterol, mg/dL & $192.3 \pm 25.0$ & $185.5 \pm 26.7$ & $193.0 \pm 24.2$ & $198.4 \pm 22.4$ & $<0.001$ \\
\hline Triglyceride, mg/dL & $94.3 \pm 48.6$ & $55.9 \pm 9.7$ & $82.1 \pm 10.8$ & $145.2 \pm 52.1$ & $<0.001$ \\
\hline $\mathrm{LDL}-\mathrm{C}, \mathrm{mg} / \mathrm{dL}$ & $116.1 \pm 22.2$ & $107.9 \pm 22.3$ & $117.5 \pm 21.0$ & $122.9 \pm 20.6$ & $<0.001$ \\
\hline $\mathrm{HDL}-\mathrm{C}, \mathrm{mg} / \mathrm{dL}$ & $60.9 \pm 13.2$ & $66.9 \pm 13.3$ & $61.7 \pm 12.0$ & $54.1 \pm 10.9$ & $<0.001$ \\
\hline Creatinine, $\mathrm{mg} / \mathrm{dL}$ & $0.8 \pm 0.2$ & $0.8 \pm 0.2$ & $0.8 \pm 0.2$ & $0.9 \pm 0.2$ & $<0.001$ \\
\hline Fasting glucose, mg/dL & $96.0 \pm 8.8$ & $92.4 \pm 7.9$ & $96.2 \pm 8.3$ & $99.5 \pm 8.9$ & $<0.001$ \\
\hline $\mathrm{HbA} 1 \mathrm{C}, \%$ & $5.4 \pm 0.4$ & $5.4 \pm 0.4$ & $5.4 \pm 0.4$ & $5.5 \pm 0.4$ & $<0.001$ \\
\hline Uric acid, mg/dL & $4.9 \pm 1.2$ & $4.6 \pm 1.2$ & $4.9 \pm 1.2$ & $5.3 \pm 1.2$ & $<0.001$ \\
\hline Categorical CACS, n (\%) & & & & & 0.001 \\
\hline 0 & $1061(84.9)$ & 370 (89.6) & $366(86.3)$ & $325(78.7)$ & \\
\hline $1-10$ & $69(5.5)$ & $16(3.9)$ & $23(5.4)$ & $30(7.3)$ & \\
\hline $11-100$ & $90(7.2)$ & $18(4.4)$ & $29(6.8)$ & $43(10.4)$ & \\
\hline $101-400$ & $25(2.0)$ & $6(1.5)$ & $5(1.2)$ & $14(3.4)$ & \\
\hline$>400$ & $5(0.4)$ & $3(0.7)$ & $1(0.2)$ & $1(0.2)$ & \\
\hline Any plaque, n (\%) & $257(20.6)$ & $61(14.8)$ & $82(19.3)$ & $114(27.6)$ & $<0.001$ \\
\hline Calcified plaque, n (\%) & $157(12.6)$ & $38(9.2)$ & $50(11.8)$ & $69(16.7)$ & 0.004 \\
\hline Non-calcified plaque, n (\%) & $120(9.6)$ & $27(6.5)$ & $35(8.3)$ & $58(14.0)$ & 0.001 \\
\hline Mixed plaque, n (\%) & $32(2.6)$ & $5(1.2)$ & $9(2.1)$ & $18(4.4)$ & 0.013 \\
\hline
\end{tabular}

Values are given as the mean \pm standard deviation or number (\%)

$P$-value of $<0.05$ was considered significant

$B M I$ Body mass index, BP Blood pressure, CACS Coronary artery calcium score, CAD Coronary artery disease, HbA1C Hemoglobin A1C, HDL-C High-density lipoprotein cholesterol, $L D L-C$ Low-density lipoprotein cholesterol, TyG Triglyceride glucose

non-calcified (OR 1.581, 95\% CI 1.002-2.493, $P=0.049$ ) and mixed plaque (OR 2.419, 95\% CI 1.051-5.569, $P=0.038$ ) (Table 3).

\section{Optimal TyG index cut-off for predicting subclinical CAD}

The ROC analysis showed that the optimal TyG index cut-off for predicting subclinical CAD, as determined using the Youden index, is 8.44 (sensitivity: $47.9 \%$; specificity: 68.5\%; AUC: 0.600; 95\% CI: 0.561-640; $P<0.001$ ) (Additional file 3: Figure S3). The predictive power of TyG levels greater than 8.44 for CAD significantly improved after taking into account age $\geq 65$ years (TyG $>8.44$ vs. TyG $>8.44 \mathrm{mg} / \mathrm{dL}$ with age $\geq 65$ years; AUC: 0.580 vs. $0.632 ; P<0.001)$ and both age $\geq 65$ years and male sex $($ TyG $>8.44$ vs. TyG $>8.44$ with age $\geq 65$ years and male sex; AUC: 0.580 vs. $0.745 ; P<0.001$ ) (Table 4 ).

\section{Discussion}

Individuals without traditional CVRFs have been considered relatively healthy and at low risk of developing atherosclerosis. Recently, PESA study reported that the prevalence of subclinical atherosclerosis in 4184 individuals without conventional CVRFs was 49.7\%; however, this study had limitation in that obesity was not considered as traditional CVRFs. In the present study, we identified that the overall prevalence of CAD in asymptomatic CVRF-free Korean population was approximately 21\% using same CVRFs criteria of PESA after including obesity in the CVRFs definition. The prevalence in those younger than 65 years was $18.5 \%$, but the rate was approximately three-times higher in individuals $\geq 65$ years. In addition, men had a significantly higher prevalence of CAD than women $(33.8 \%$ vs. $8.9 \%)$. We were able to confirm that 
Table 2 Association between clinical variables and subclinical CAD

\begin{tabular}{lll}
\hline Variables & Univariate & \\
\cline { 2 - 3 } & OR (95\% Cl) & $P$ \\
\hline Age, 1 years increase & $1.116(1.092-1.141)$ & $<0.001$ \\
Male & $5.233(3.810-7.188)$ & $<0.001$ \\
Systolic BP, per 1 mmHg increase & $1.051(1.037-1.065)$ & $<0.001$ \\
Diastolic BP, per 1 mmHg increase & $1.060(1.043-1.078)$ & $<0.001$ \\
BMI, 1 kg/m ${ }^{2}$ increase & $1.221(1.121-1.331)$ & $<0.001$ \\
Family history of CAD & $1.268(0.884-1.819)$ & 0.198 \\
TyG index tertile & & \\
$\quad$ I (lowest) & 1 & - \\
$\quad$ II & $1.384(0.962-1.990)$ & 0.080 \\
III (highest) & $2.200(1.555-3.113)$ & $<0.001$ \\
LCL-C, per 1 mg/dL increase & $1.010(1.003-1.016)$ & 0.004 \\
HDL-C, per 1 mg/dL increase & $0.978(0.967-0.988)$ & $<0.001$ \\
$\begin{array}{l}\text { HbA1C, per 1\% increase } \\
\text { Uric acid, per 1 mg/dL increase }\end{array}$ & $1.379(0.942-2.018)$ & 0.098 \\
\hline $\begin{array}{l}\text { P-value of < 0.05 was considered significant } \\
\text { BMI Body mass index, BP Blood pressure, CAD Coronary artery disease, Cl } \\
\text { Confidence interval, HbA1C Haemoglobin A1C, HDL-C High-density lipoprotein } \\
\text { cholesterol, LDL-C Low-density lipoprotein cholesterol, OR Odds ratio }\end{array}$ &
\end{tabular}

Table 3 Impact of TyG index on coronary plaques

\begin{tabular}{lll}
\hline Variables & OR $(95 \% \mathrm{Cl})$ & $P$ \\
\hline Any plaque & & \\
TyG index, per 1 increase & & $<0.001$ \\
Model 1 & $2.158(1.605-2.903)$ & 0.036 \\
Model 2 & $1.473(1.026-2.166)$ & \\
Calcified plaque & & $<0.001$ \\
TyG index, per 1 increase & & 0.072 \\
Model 1 & $2.016(1.416-2.870)$ & \\
Model 2 & $1.488(0.965-2.295)$ & $<0.001$ \\
Non-calcified plaque & & 0.049 \\
TyG index, per 1 increase & & \\
Model 1 & $2.294(1.549-3.398)$ & \\
Model 2 & $1.581(1.002-2.493)$ & 0.002 \\
Mixed plaque & & 0.038 \\
TyG index, per 1 increase & &
\end{tabular}

$P$-value of $<0.05$ was considered significant

$B M I$ Body mass index, $B P$ Blood pressure, $\mathrm{Cl}$ Confidence interval, OR Odds ratio, TyG Triglyceride glucose

Model 1: Unadjusted

Model 2: Adjusted for age, male sex, systolic and diastolic BP, BMI, and the levels of LDL-C, HDL-C, and uric acid
Table 4 Comparison of ROC models related to the cut-offs of TyG index for predicting subclinical CAD

\begin{tabular}{ll}
\hline ROC Models & AUC $(95 \% \mathrm{Cl})$ \\
\hline TyG index $\geq 8.44$ & $0.580(0.546-0.614)$ \\
TyG index $\geq 8.44$ with age $\geq 65$ years & $0.632(0.596-0.667)^{*}$ \\
TyG index $\geq 8.44$ with age $\geq 65$ years and male sex & $0.745(0.714-0.776)^{*}$ \\
\hline$P$-value of $<0.05$ was considered significant & \\
$A U C$ Area under the curve, CAD Coronary artery disease, Cl Confidence \\
interval, $L D$ - $C$ Low-density lipoprotein cholesterol, ROC Receiver \\
$\begin{array}{l}\text { operating characteristic } \\
* P<0.001 \text { vs. TyG index } \geq 8.44\end{array}$
\end{tabular}

TyG index has significant value in predicting subclinical CAD in individuals without CVRFs. In terms of specific coronary plaque subtypes, TyG index was independently associated with an increased risk of non-calcified or mixed coronary plaques in this population.

It is important to identify independent predictors of subclinical CAD in individuals with a low CV risk burden considering the frequency of major atherosclerotic $\mathrm{CV}$ events in this population. Moreover, recent data showing that non-obstructive coronary plaques contribute to an increase in adverse $\mathrm{CV}$ events also suggest the significance of identifying predictors for subclinical CAD [24-26]. Previous studies had reported that TyG index was a reliable marker of IR and was associated with coronary artery calcification in a general population. However, the value of TyG index in detecting subclinical CAD in the absence of traditional CVRFs has not been evaluated. One interesting finding of the present study is that TyG index was independently associated with the risk of non-calcified plaques in the absence of CVRFs. Based on the results of a recent meta-analysis [27], noncalcified plaque could be associated with an increased risk of acute coronary syndrome events. Therefore, this finding supports the hypothesis that TyG index is an important CV risk factor independent of traditional CVRFs.

Compared with the results of PESA study, the prevalence of subclinical atherosclerosis was relatively low in the present study. This discrepancy might be related to the differences in (1) the method of measuring subclinical atherosclerosis, (2) the definition of CVRFs, and (3) the ethnicity of the participants. As is well known, obesity is strongly associated with atherosclerosis even in metabolically healthy population [28]. Considering that all the participants in our study were Korean, we excluded individuals with a BMI $\geq 25.0 \mathrm{~kg} / \mathrm{m}^{2}$, which is the cut-off for the definition of obesity in Asian populations. Thus, it is possible that the prevalence of subclinical atherosclerosis was overestimated in the PESA study.

The present study identified the optimal cut-off of TyG index for predicting CAD in asymptomatic CVRFfree individuals. However, the AUC of 8.44 might be 
poor, suggesting that it is difficult to predict the presence of subclinical CAD based on TyG index alone. Although the predictive value improved after considering non-modifiable clinical factors, including old age and male sex, it remained only moderately powerful. However, this may be meaningful on a population level. Although data on the association between TyG index levels and adverse CV events in individuals with a low risk burden are limited, our result implies that it is important to keep the TyG index below the optimal cut-off in this population.

Some limitations were present in our study. First, all participants voluntarily visited the hospitals and participated in the general health examination. Thus, selection bias may be present. Second, the results may not be generalizable to other populations because all participants were Korean. Finally, the routine use of CCTA examinations in asymptomatic individuals remains unjustified, despite advances that have addressed its shortcomings [29]. Despite these limitations, the present study could provide a clinical implication in that we identified the independent predictive value of TyG index for subclinical CAD in the absence of CVRFs, especially in Asian population.

\section{Conclusions}

In summary, TyG index is an independent marker of the presence of CAD, especially non-calcified or mixed plaques, in asymptomatic individuals without traditional CVRFs. Further large-scale prospective studies might be necessary to confirm the significance of TyG index in primary prevention of CAD in individuals who have conventionally been considered healthy.

\section{Supplementary information}

Supplementary information accompanies this paper at https://doi.org/10. 1186/s12944-020-1187-0.

Additional file 1: Figure S1. Overview of the study population.

Additional file 2: Figure S2. Prevalence of subclinical CAD according to old age and sex.

Additional file 3: Figure S3. Optimal TyG cut-offs for predicting subclinical CAD.

\section{Abbreviations}

BMI: Body mass index; CACS: Coronary artery calcium score; CAD: Coronary artery disease; CCTA: Coronary computed tomography angiography; $\mathrm{Cl}$ : Confidence interval; CV: Cardiovascular; CVRFs: Cardiovascular risk factors; HbA1C: Hemoglobin A1C; HDL-C: High-density lipoprotein cholesterol; LCLC: Low-density lipoprotein cholesterol; OR: Odds ratio; ROC: Receiver operating characteristic; TyG: Triglyceride glucose

\section{Acknowledgements}

The Medical Information Center of Ulsan University Hospital supported this work in terms of statistical analysis.

\section{Authors' contributions}

GMP, YRC, KBW, YJY, SP, SHA, YGK, DHY, and JWK contributed to the conception or design of the work. GMP, THL, HKK, JC, SWL, YHK, SJK, and SGL contributed to the acquisition, analysis, or interpretation of data for the work. GMP and YRC drafted the manuscript. KBW critically revised the manuscript. All authors gave final approval and agree to be accountable for all aspects of work ensuring integrity and accuracy.

\section{Funding}

This research was supported by the Basic Science Research Program through the National Research Foundation of Korea funded by the Ministry of Education (2018R1D1A3B07043344).

\section{Availability of data and materials}

The datasets used and analyzed during the current study are available from the corresponding author on reasonable request.

\section{Ethics approval and consent to participate}

The study protocol was approved by the local Institutional Review Board of the Asan Medical Center, and informed consent for the procedure was obtained from each participant.

\section{Consent for publication}

Not applicable.

\section{Competing interests}

The authors declare that they have no competing interests.

\section{Author details}

'Division of Cardiology, Ulsan University Hospital, University of Ulsan College of Medicine, 877 Bangeojinsunhwando-ro, Dong-gu, Ulsan 44033, Republic of Korea. ${ }^{2}$ Division of Cardiology, Dong-A University Hospital, Busan, Republic of Korea. ${ }^{3}$ Division of Cardiology, Asan Medical Center, University of Ulsan College of Medicine, Seoul, Republic of Korea. ${ }^{4}$ Medical information Center, Ulsan University Hospital, Ulsan, Republic of Korea. ${ }^{5}$ Division of Radiology, Asan Medical Center, University of Ulsan College of Medicine, Seoul, Republic of Korea. ${ }^{6}$ Division of Health Screening and Promotion Center, Asan Medical Center, University of Ulsan College of Medicine, Seoul, Republic of Korea.

Received: 2 November 2019 Accepted: 5 January 2020

Published online: 14 January 2020

\section{References}

1. Khot UN, Khot MB, Bajzer CT, Sapp SK, Ohman EM, Brener SJ, Ellis SG, Lincoff AM, Topol EJ. Prevalence of conventional risk factors in patients with coronary heart disease. JAMA. 2003;290:898-904.

2. Lloyd-Jones DM, Hong Y, Labarthe D, Mozaffarian D, Appel LJ, Van Horn L, Greenlund K, Daniels S, Nichol G, Tomaselli GF, Arnett DK, Fonarow GC, Ho PM, Lauer MS, Masoudi FA, Robertson RM, Roger V, Schwamm LH, Sorlie P, Yancy CW, Rosamond WD. Defining and setting national goals for cardiovascular health promotion and disease reduction: the American Heart Association's strategic impact goal through 2020 and beyond. Circulation. 2010;121:586-613.

3. Yusuf S, Rangarajan S, Teo K, Islam S, Li W, Liu L, Bo J, Lou Q, Lu F, Liu T, Yu L, Zhang S, Mony P, Swaminathan S, Mohan V, Gupta R, Kumar R, Vijayakumar K, Lear S, Anand S, Wielgosz A, Diaz R, Avezum A, LopezJaramillo P, Lanas F, Yusoff K, Ismail N, Iqbal R, Rahman O, Rosengren A, Yusufali A, Kelishadi R, Kruger A, Puoane T, Szuba A, Chifamba J, Oguz A, McQueen M, McKee M, Dagenais G. Cardiovascular risk and events in 17 low-, middle-, and high-income countries. N Engl J Med. 2014;371:818-27.

4. Silverman MG, Blaha MJ, Krumholz HM, Budoff MJ, Blankstein R, Sibley CT, Agatston A, Blumenthal RS, Nasir K. Impact of coronary artery calcium on coronary heart disease events in individuals at the extremes of traditional risk factor burden: the multi-ethnic study of atherosclerosis. Eur Heart J. 2014;35:2232-41.

5. Piepoli MF, Hoes AW, Agewall S, Albus C, Brotons C, Catapano AL, Cooney MT, Corrà U, Cosyns B, Deaton C, Graham I, Hall MS, Hobbs FDR, Løchen ML, Löllgen H, Marques-Vidal P, Perk J, Prescott E, Redon J, Richter DJ, Sattar $\mathrm{N}$, Smulders Y, Tiberi M, van der Worp HB, van Dis I, Verschuren WMM, Binno S. 2016 European quidelines on cardiovascular disease prevention in clinical practice: the sixth joint task force of the European Society of 
Cardiology and Other Societies on cardiovascular disease prevention in clinical practice (constituted by representatives of 10 societies and by invited experts) developed with the special contribution of the European Association for Cardiovascular Prevention \& rehabilitation (EACPR). Eur Heart J. 2016;37:2315-81

6. Fernández-Friera L, Fuster V, López-Melgar B, Oliva B, García-Ruiz JM, Mendiguren J, Bueno H, Pocock S, Ibáñez B, Fernández-Ortiz A, Sanz J. Normal LDL-cholesterol levels are associated with subclinical atherosclerosis in the absence of risk factors. J Am Coll Cardiol. 2017;70:2979-91.

7. Won KB, Park GM, Yang YJ, Ann SH, Kim YG, Yang DH, Kang JW, Lim TH, Kim HK, Choe J, Lee SW, Kim YH, Kim SJ, Lee SG. Independent role of lowdensity lipoprotein cholesterol in subclinical coronary atherosclerosis in the absence of traditional cardiovascular risk factors. Eur Heart J Cardiovasc Imaging. 2019;20:866-72

8. Bonora E, Kiechl S, Willeit J, Oberhollenzer F, Egger G, Meigs JB, Bonadonna RC, Muggeo M. Insulin resistance as estimated by homeostasis model assessment predicts incident symptomatic cardiovascular disease in caucasian subjects from the general population: the Bruneck study. Diabetes Care. 2007:30:318-24.

9. Eddy D, Schlessinger L, Kahn R, Peskin B, Schiebinger R. Relationship of insulin resistance and related metabolic variables to coronary artery disease: a mathematical analysis. Diabetes Care. 2009;32:361-6.

10. Simental-Mendía LE, Rodríguez-Morán M, Guerrero-Romero F. The product of fasting glucose and triglycerides as surrogate for identifying insulin resistance in apparently healthy subjects. Metab Syndr Relat Disord. 2008:6:299-304

11. Vasques AC, Novaes FS, de Oliveira MS, Souza JR, Yamanaka A, Pareja JC, Tambascia MA, Saad MJ, Geloneze B. TyG index performs better than HOMA in a Brazilian population: a hyperglycemic clamp validated study. Diabetes Res Clin Pract. 2011:93:e98-e100.

12. Guerrero-Romero F, Villalobos-Molina R, Jiménez-Flores JR, Simental-Mendia LE, Méndez-Cruz R, Murguía-Romero M, Rodríguez-Morán M. Fasting triglycerides and glucose index as a diagnostic test for insulin resistance in young adults. Arch Med Res. 2016:47:382-7.

13. Kim MK, Ahn CW, Kang S, Nam JS, Kim KR, Park JS. Relationship between the triglyceride glucose index and coronary artery calcification in Korean adults. Cardiovasc Diabetol. 2017;16:108.

14. Won KB, Kim YS, Lee BK, Heo R, Han D, Lee JH, Lee SE, Sung JM, Cho I, Park $H B$, Cho IJ, Chang HJ. The relationship of insulin resistance estimated by triglyceride glucose index and coronary plaque characteristics. Medicine (Baltimore). 2018;97:e10726

15. Park GM, Yun SC, Cho YR, Gil EH, Her SH, Kim SH, Jo MW, Lee MS, Lee SW, Kim YH, Yang DH, Kang JW, Lim TH, Kim BJ, Koh JM, Kim HK, Choe J, Park SW, Park SJ. Prevalence of coronary atherosclerosis in an Asian population: findings from coronary computed tomographic angiography. Int J Cardiovasc Imaging. 2015;31:659-68.

16. Wilson PW, D'Agostino RB, Levy D, Belanger AM, Silbershatz H, Kannel WB. Prediction of coronary heart disease using risk factor categories. Circulation. 1998:97:1837-47.

17. Goff DC Jr, Lloyd-Jones DM, Bennett G, Coady S, D'Agostino RB Sr, Gibbons R, Greenland P, Lackland DT, Levy D, O'Donnell CJ, Robinson JG, Schwartz JS, Shero ST, Smith SC Jr, Sorlie P, Stone NJ, Wilson PWF. 2013 ACC/AHA guideline on the assessment of cardiovascular risk: a report of the American College of Cardiology/American Heart Association task force on practice guidelines. J Am Coll Cardiol. 2014;63:2935-59.

18. Bansal S, Wackers FJ, Inzucchi SE, Chyun DA, Davey JA, Staib LH, Young LH. Five-year outcomes in high-risk participants in the detection of ischemia in asymptomatic diabetics (DIAD) study: a post hoc analysis. Diabetes Care. 2011;34:204-9.

19. Christner JA, Braun NN, Jacobsen MC, Carter RE, Kofler JM, McCollough CH. Size-specific dose estimates for adult patients at $\mathrm{CT}$ of the torso. Radiology. 2012;265:841-7.

20. Raff GL, Abidov A, Achenbach S, Berman DS, Boxt LM, Budoff MJ, Cheng V, DeFrance T, Hellinger JC, Karlsberg RP. SCCT guidelines for the interpretation and reporting of coronary computed tomographic angiography. J Cardiovasc Comput Tomogr. 2009:3:122-36.

21. Agatston AS, Janowitz WR, Hildner FJ, Zusmer NR, Viamonte M Jr, Detrano R. Quantification of coronary artery calcium using ultrafast computed tomography. J Am Coll Cardiol. 1990;15:827-32.

22. Leber AW, Becker A, Knez A, von Ziegler F, Sirol M, Nikolaou K, Ohnesorge B, Fayad ZA, Becker CR, Reiser M, Steinbeck G, Boekstegers P. Accuracy of 64-slice computed tomography to classify and quantify plaque volumes in the proximal coronary system: a comparative study using intravascular ultrasound. J Am Coll Cardiol. 2006;47:672-7.

23. Hausleiter J, Meyer T, Hadamitzky M, Kastrati A, Martinoff S, Schömig A. Prevalence of noncalcified coronary plaques by 64-slice computed tomography in patients with an intermediate risk for significant coronary artery disease. J Am Coll Cardiol. 2006;48:312-8.

24. Motoyama $S$, Ito $H$, Sarai $M$, Kondo $T$, Kawai $H$, Nagahara $Y$, Harigaya $H$, Kan S, Anno H, Takahashi H, Naruse H, Ishii J, Hecht H, Shaw LJ, Ozaki Y, Narula J. Plaque characterization by coronary computed tomography angiography and the likelihood of acute coronary events in mid-term follow-up. J Am Coll Cardiol. 2015;66:337-46.

25. Pizzi C, Xhyheri B, Costa GM, Faustino M, Flacco ME, Gualano MR, Fragassi G, Grigioni F, Manzoli L. Nonobstructive versus obstructive coronary artery disease in acute coronary syndrome: a meta-analysis. J Am Heart Assoc 2016;5:e004185.

26. Conte E, Annoni A, Pontone G, Mushtaq S, Guglielmo M, Baggiano A, Volpato V, Agalbato C, Bonomi A, Veglia F, Formenti A, Fiorentini C, Bartorelli AL, Pepi M, Andreini D. Evaluation of coronary plaque characteristics with coronary computed tomography angiography in patients with non-obstructive coronary artery disease: a long-term follow-up study. Eur Heart J Cardiovasc Imaging. 2017:18:1170-8.

27. Thomsen C, Abdulla J. Characteristics of high-risk coronary plaques identified by computed tomographic angiography and associated prognosis: a systematic review and meta-analysis. Eur Heart J Cardiovasc Imaging. 2016:17:120-9.

28. Chang Y, Kim BK, Yun KE, Cho J, Zhang Y, Rampal S, Zhao D, Jung HS, Choi Y, Ahn J, Lima JA, Shin H, Guallar E, Ryu S. Metabolically-healthy obesity and coronary artery calcification. J Am Coll Cardiol. 2014;63:2679-86.

29. Fuchs TA, Stehli J, Bull S, Dougoud S, Clerc OF, Herzog BA, Buechel RR, Gaemperli O, Kaufmann PA. Coronary computed tomography angiography with model-based iterative reconstruction using a radiation exposure similar to chest X-ray examination. Eur Heart J. 2014:35:1131-6.

\section{Publisher's Note}

Springer Nature remains neutral with regard to jurisdictional claims in published maps and institutional affiliations.

Ready to submit your research? Choose BMC and benefit from:

- fast, convenient online submission

- thorough peer review by experienced researchers in your field

- rapid publication on acceptance

- support for research data, including large and complex data types

- gold Open Access which fosters wider collaboration and increased citations

- maximum visibility for your research: over $100 \mathrm{M}$ website views per year

At $\mathrm{BMC}$, research is always in progress.

Learn more biomedcentral.com/submission 